\title{
Orthopedics Orthopédie
}

\section{Canine cranial cruciate ligament rupture in profile: 2002-2007}

\author{
Greg Harasen
}

$\mathbf{R}$ upture of the cranial cruciate ligament (CCL) is the most common orthopedic condition in the dog... and nearly every paper written on the topic begins with that line! The demographics of this problem within our practice have been examined on 2 previous occasions, covering cases treated from 1983 to 1994 (1) and from 1997 to 2002 (2). This article analyses cases from October 1, 2002, to September 30, 2007, and makes comparisons to the previous 2 studies.

Records were examined from 421 surgical procedures on 328 dogs. One hundred and thirty-one procedures were done on 100 small breed dogs, while 290 procedures were done on 228 large breed dogs. Fifteen kilograms was used as the dividing line between large and small breed dogs; however, some obese small breed dogs, $>15 \mathrm{~kg}$, were still considered to be in the small breed category. All small breed dogs were treated surgically by using an extracapsular suture technique (3), fastened with a locking loop knot (4) or a crimp clamp (5). Of the large breed cases, 232 were treated surgically with a tibial plateau leveling osteotomy (TPLO) (6) and 58 received an extracapsular repair. In total, 232 TPLOs and 189 extracapsular repairs were performed.

The original survey showed a predominantly female $(65 \%$, female or female spayed) and small breed (65\%) population with CCL ruptures (1). In the 2 nd survey, these figures shifted significantly to $61 \%$ large breed dogs with $53 \%$ females or female spayed (2). In the current survey, $69 \%$ of cases were in large breed dogs, of which $53 \%$ were females or female spayed. In the small breeds, $58 \%$ were males or male neutered. Considering small and large breed cases in total, the distribution between the sexes was exactly equal.

The breed distribution in our patients was similar to that in the past surveys, with $23 \%$ of large breed cases occurring in Labradors or Labrador crosses. Rottweilers and rottweiler crossbreds, German shepherds and shepherd crossbreds, along with golden retrievers made up $11.4 \%, 10.7 \%$, and $7.6 \%$ of our large breed cases, respectively. We observed that $9 \%$ of large breed cases occurred in dogs identified as huskies or husky crossbreds; a percentage much greater than the proportion of huskies in our practice population. Similarly, chow chows and their related crossbreds accounted for $2.8 \%$ of cases, while Great Pyrennes, Saint Bernards, mastiffs, springer spaniels, and related crossbreds each accounted for $2.4 \%$ of cases; numbers in

Animal Clinic of Regina, 1800 Garnet Street, Regina, Saskatchewan S4T 2Z2.

excess of their frequency in our

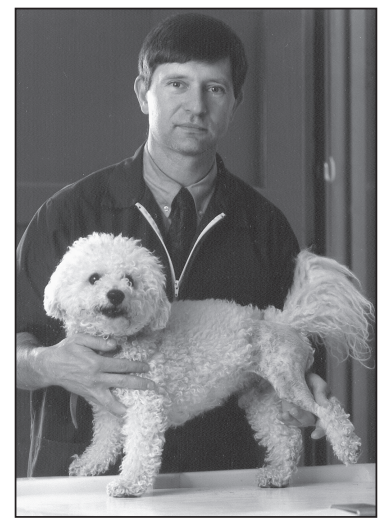
general population. Bichon frises (35\%), cocker spaniels (17\%), poodles (19\%), lhasa apsos, (7\%), and crossbreds of these breeds accounted for nearly 8 out of 10 of our small breed cases.

The mean weight of our large breed cases was $38 \mathrm{~kg}$ with a range of 16.8 to $89.5 \mathrm{~kg}$. Small breed cases averaged $10 \mathrm{~kg}$ with a range of 3.6 to $22.2 \mathrm{~kg}$.

The mean age of our large breeds was $5.5 \mathrm{y}$, with a range of 9 mo to $13 \mathrm{y}$. The small breeds averaged $7.4 \mathrm{y}$, but the range was worthy of note. Our oldest case was $15 \mathrm{y}$, but none were younger than $4 \mathrm{y}$. One might view these numbers in light of published theories on the etiology and pathogenesis of cruciate rupture. Degeneration of the CCL has been described as an aging change in many dogs (7). Conversely, "cruciate disease" has been a phrase coined to describe the genetically determined degeneration and rupture that occurs at a relatively early age, especially in large breed dogs (8). These data suggest that the generally older profile of small breed cruciate patients is consistent with aging degeneration, while the occurrence of cruciate disease in a generally younger population of large breed dogs, some under $1 \mathrm{y}$ of age, supports the suggestion of a genetic etiology. An overwhelming number of small breed cases trace lineage to 4 breeds, making a genetic component in these dogs highly likely as well.

Another statistic that may be interpreted as contributing to the idea of a genetic etiology for CCL rupture is the proportion of dogs that subsequently rupture the CCL in the contralateral limb. The 2 previous surveys $(1,2)$ identified $30 \%$ and $27 \%$ of dogs that ruptured their contralateral CCL. In this survey, 37\% of large and $45 \%$ of small breed dogs ruptured their contralateral CCL. As significant as these latest figures are, they certainly understate the problem. There are undoubtedly dogs that were lost to follow-up that ruptured their contralateral CCL and there will be dogs that rupture their other CCL after the end of this study period.

Meniscal tears, especially to the medial meniscus, were noted in $37 \%$ of small and $42 \%$ of large breed dogs. This is similar to the $48 \%$ of dogs in the 1997-2002 survey noted to have meniscal pathology (2), and similar to previously published estimates (9-12). Again, as in the previous studies, there was not a significant difference between small and large dogs in the incidence of meniscal lesions.

A feature of cruciate disease that has received increasing attention in recent years has been partial CCL tears. In the 1997-2002 study (2), 13\% of total cases were categorized as 
partial tears at surgery. In this review, $16 \%$ of total cases were partial tears; however, the breakdown between large and small breeds was significant. Twenty-one percent of large breed cases were confirmed as partial tears, while only $5 \%$ of small breed cases fell into this category.

The previous 2 studies only examined 1 complication, lameness, that was noted in the medical record more than 2 mo postoperatively $(1,2)$. Such lameness, of varying degrees, was noted in $30 \%$ and $23 \%$ of large and $7 \%$ and $11 \%$ of small breed dogs, respectively. All cases in those previous 2 studies were treated with an extracapsular repair. The latest study looked more closely at complications since the majority of large breed cases (232 of 290) were treated with TPLO. Overall, 9\% of large and $4 \%$ of small breed dogs had lameness, as reported by the owner, more than 2 mo postoperatively. Suture line infections occurred in $5.9 \%$ of large breed cases and $4.6 \%$ of small breeds. The criterion used to determine the presence of a postoperative infection was where the follow-up veterinarian deemed the prescribing of antibiotics to be warranted. In an additional $6 \%$ of large breed cases, a variety of other complications were reported, including seroma formation, postoperative bleeding, lick granuloma formation at the surgery site, and patellar fracture.

Comparing the occurance of complications in large dogs treated with TPLO with that in those treated with extracapsular repair, $15.5 \%$ of TPLO dogs experienced at least 1 complication, while $24 \%$ of extracapsular dogs experienced 1 or more complications. Complications in the TPLO group included infections, lick granulomas, lameness more than 2 mo postoperatively, seroma, excessive bleeding postoperatively, patellar fracture, and osteotomy/surgical hardware failure. Postoperative lameness beyond 2 mo was seen in $7.3 \%$ of TPLO cases compared with $15.5 \%$ of extracapsular cases, while infections occurred in $5.2 \%$ of TPLO cases compared with $8.6 \%$ in extracapsular cases; these differences are noteworthy. These figures compare favorably with published post-TPLO complication rates that exceed $20 \%$ $(13,14)$; however, our numbers certainly underestimate the true complication rate since no effort was made to formally survey owners or referring veterinarians to determine complications that we were not informed of or did not note in our records.
The limited number of extracapsular repairs done on large dogs during this period may also affect the validity of these results; however, the greater rate of complications in the extracapsular group is interesting and runs contrary to conventional wisdom, if not statistical analysis, in this review.

\section{References}

1. Harasen G. A retrospective study of 165 cases of rupture of the canine cranial cruciate ligament. Can Vet J 1995;36:250-251.

2. Harasen G. Canine cranial cruciate ligament rupture in profile. Can Vet J 2003;44:845-846.

3. Piermattei DL, Flo GL, DeCamp CE. Handbook of Small Animal Orthopedics and Fracture Repair, 4th ed. St Louis, Elsevier-Saunders, 2006:586-590.

4. McKee WM, Miller A. A self-locking knot for lateral fabellotibial suture stabilization of the cranial cruciate ligament deficient stifle in the dog. Vet Comp Orthop Traumatol 1999;12:78-80.

5. Anderson CC, Tomlinson JL, Daly WR, Carson WL, Payne JT, Wagner-Mann CC. Biomechanical evaluation of a crimp clamp system for loop fixation of monofilament nylon leader material used for stabilization of the canine stifle joint. Vet Surg 1998;27:533-539.

6. Slocum B, Devine-Slocum T. Tibial plateau leveling osteotomy for repair of cranial cruciate ligament rupture in the canine. In: Roush JK, ed. Stifle Surgery. Vet Clin North Amer: Small Anim Pract 1993; 23:777-795.

7. Harari J. How I treat cranial cruciate ligament injury. Compend Contin Educ Pract Vet 1996;18:1185-1187.

8. Wilke VL, Conzemius MG, Kinghorn BP, Macrossan PE, Weiguo C, Rothschild F. Inheritance of rupture of the cranial cruciate ligament in Newfoundlands. J Am Vet Med Assoc 2006;228:61-64.

9. Elkins AD, Pechman R, Kearney MT, Herron M. A retrospective study evaluating the degree of degenerative joint disease in the stifle joint of dogs following surgical repair of anterior cruciate ligament rupture. J Am Anim Hosp Assoc 1991;27:533-539.

10. Moore KW, Read RA. Cranial cruciate ligament rupture in the dog: a retrospective study comparing surgical techniques. Aust Vet J 1995;72:281-285.

11. Bennett D, May C. Meniscal damage associated with cruciate disease in the dog. J Small Anim Pract 1991;32:111-117.

12. Flo GL. Classification of meniscal lesions in twenty-six consecutive canine meniscectomies. J Am Anim Hosp Assoc 1983;19:335-340.

13. Pacchiana PD, Morris E, Gillings SL, Jessen CR, Lipowitz AJ. Surgical and postoperative complications associated with tibial plateau leveling osteotomy in dogs with cranial cruciate ligament rupture: 397 cases (1998-2001). J Am Vet Med Assoc 2003;222:184-193.

14. Priddy NH, Tomlinson JL, Dodam JR, Hornbostel JE. Complications with and owner assessment of tibial plateau leveling osteotomy for treatment of cranial cruciate ligament rupture in dogs: 193 cases (1997-2001). J Am Vet Med Assoc 2203;222:1727-1732. 